\title{
Transvenous embolization of brain arteriovenous malformations: a review of techniques, indications, and outcomes
}

\author{
${ }^{*}$ Ching-Jen Chen, MD, ${ }^{1}$ Pedro Norat, MD, ${ }^{1}$ Dale Ding, MD, ${ }^{2}$ George A. C. Mendes, MD, ${ }^{3}$ \\ Petr Tvrdik, PhD, ${ }^{1}$ Min S. Park, MD, ${ }^{1}$ and M. Yashar Kalani, MD, PhD ${ }^{1}$
}

\begin{abstract}
${ }^{1}$ Department of Neurological Surgery, University of Virginia Health System, Charlottesville, Virginia; ${ }^{2}$ Department of Neurosurgery, Barrow Neurological Institute, Phoenix, Arizona; and 'Department of Interventional Neuroradiology, Hôpital Dupuytren, Centre Regional Hospitalier Universitaire de Limoges, France
\end{abstract}

\begin{abstract}
Endovascular embolization of brain arteriovenous malformations (AVMs) is conventionally performed from a transarterial approach. Transarterial AVM embolization can be a standalone treatment or, more commonly, used as a neoadjuvant therapy prior to microsurgery or stereotactic radiosurgery. In contrast to the transarterial approach, curative embolization of AVMs may be more readily achieved from a transvenous approach. Transvenous embolization is considered a salvage therapy in contemporary AVM management. Proposed indications for this approach include a small (diameter < $3 \mathrm{~cm}$ ) and compact AVM nidus, deep AVM location, hemorrhagic presentation, single draining vein, lack of an accessible arterial pedicle, exclusive arterial supply by perforators, and en passage feeding arteries. Available studies of transvenous AVM embolization in the literature have reported high complete obliteration rates, with reasonably low complication rates. However, evaluating the efficacy and safety of this approach is challenging due to the limited number of published cases. In this review the authors describe the technical considerations, indications, and outcomes of transvenous AVM embolization.
\end{abstract}

https://thejns.org/doi/abs/10.3171/2018.3.FOCUS18113

KEYWORDS arteriovenous malformation; transvenous; embolization; cure; endovascular

$\mathrm{B}$ RAIN arteriovenous malformations (AVMs) are characterized by abnormal, high-flow connections between feeding arteries and draining veins with an intervening plexus of abnormal vessels, which comprises the nidus ${ }^{17,41}$ Direct intranidal arteriovenous fistulas can also be found within AVMs, and the relative contribution of fistulous versus nidal components varies among AVMs. ${ }^{4,24}$ The most common presentations of AVMs include hemorrhages, seizures, headaches, and progressive neurological deficits due to chronic vascular steal.,13,14 The majority of AVM-associated morbidity and mortality can be attributed to hemorrhage secondary to rupture of the nidus or flow-related aneurysms. ${ }^{3,16,47}$ The inherent lack of normal smooth muscle properties, as a result of aberrant angiogenesis and vascular remodeling in the vascular beds of AVMs, predisposes these lesions to rupture. .,30,55 $^{2}$ Risk factors for AVM rupture include prior hemorrhage, associated arterial aneurysms, exclusively deep venous drainage, and deep AVM location. ${ }^{19,28}$ Despite this, elimination of hemorrhage risk by extirpation or endoluminal closure of the nidus remains the primary goal of AVM treatment. ${ }^{11,32,52,53}$

Contemporary management strategies are dictated by the angioarchitecture, location, and presentation of AVMs. ${ }^{5,27}$ Currently employed treatment options include microsurgery, stereotactic radiosurgery, and endovascular embolization as standalone or combination therapies. ${ }^{12,15,18,31,45}$ Despite unresolved controversies regarding the choice of treatment modality, obliteration of the AVM nidus with preservation of normal venous drainage remains

ABBREVIATIONS AVM = arteriovenous malformation; DAVF = dural arteriovenous fistula; DSA = digital subtraction angiography; ICV = internal cerebral vein; $m$ RS = modified Rankin Scale; NBCA = N-butyl cyanoacrylate; PHIL = precipitating hydrophobic injectable liquid; TRENSH = transvenous retrograde nidus sclerotherapy under controlled hypotension.

SUBMITTED February 28, 2018. ACCEPTED March 28, 2018

INCLUDE WHEN CITING DOI: 10.3171/2018.3.FOCUS18113.

${ }^{*}$ C.J.C. and P.N. contributed equally to this work. 
the common theme of all interventions. Premature venous occlusion or ligation can result in nidus engorgement and disastrous hemorrhagic complications. Serial disconnection of an AVM's arterial supply prior to the final ligation of the draining vein is a fundamental principle of AVM resection. ${ }^{6,51}$ Similarly, progressive AVM devascularization via occlusion of arterial feeders and nidal penetration by liquid embolysates can be achieved with endovascular embolization, which is conventionally performed from a transarterial approach. ${ }^{49}$ Despite its challenges in achieving adequate nidal penetration without early compromise of venous drainage, transvenous embolization has recently been introduced as a potentially curative intervention for carefully selected AVMs. In this review, we describe the techniques, indications, and outcomes of transvenous AVM embolization.

\section{Technical Considerations}

The rising popularity of transvenous AVM embolization stems from successful transvenous treatment paradigms for dural arteriovenous fistulas (DAVFs). Pioneering work on transvenous embolization of transverse-sigmoid sinus DAVFs and carotid-cavernous fistulas by Halbach et al. described transvenous navigation of microcatheters into the sites of venous drainage, with delivery of coils or liquid embolysate to achieve DAVF obliteration. ${ }^{21,22}$ However, the transvenous approach for AVMs faced significant challenges because the fistulous connections in AVM nidi are predominantly between arterioles and venules. Because these foci of arteriovenous shunting are more distally located and have more tortuous courses than dural venous sinuses (i.e., for transvenous embolization of DAVFs), they are typically more difficult to access from a transvenous route. ${ }^{24}$

A model for transvenous AVM embolization was first conceptualized by Massoud and Hademenos. ${ }^{37}$ The authors described the transvenous retrograde nidus sclerotherapy under controlled hypotension (TRENSH) technique using temporary systemic hypotension with or without temporary occlusion of the main arterial feeders, allowing for a more thorough permeation of an AVM nidus than could otherwise be achieved with the transarterial route, while avoiding ischemic complications that may be encountered with embolization through arterial feeders. Subsequently, Massoud et al. showed that induced systemic hypotension may decrease intranidal pressure, and thus reduce the risk of iatrogenic nidal hemorrhage using electrical network analyses that modeled transvenous AVM embolization. ${ }^{38}$ This was followed by a study by Massoud using a carotidjugular fistula-type swine AVM model that demonstrated decreased arterial feeder pressure, increased extent of retrograde nidus contrast filling, and concurrent contrast emptying through a greater number of draining veins with systemic hypotension and temporary arterial feeder occlusion. ${ }^{36}$ This experimental model formed the basis for subsequent clinical studies of transvenous AVM embolization.

Transvenous microcatheter navigation presents unique challenges due to the variability and tortuosity of the venous system that can be encountered. Although the arteri- alized veins found in AVMs have relatively thicker walls, the fragility of cortical veins unrelated to the AVM pose a greater risk of perforation than transarterial navigation. Recent advancements in the compliance and flexibility of microcatheters and microguidewires have improved the safety of transvenous catheterization and navigation. ${ }^{8}$ Despite this, defining and understanding the venous anatomy remains crucial to successfully traversing the venous system during the transvenous approach to AVMs.

In cases of difficult venous anatomy, a compliant balloon can be used in the dural venous sinus as a proximal buttress to facilitate microguidewire navigation and microcatheter tracking. ${ }^{40}$ However, navigation of two microcatheters in the venous system is not always feasible, especially in the tortuous and smaller-caliber cortical veins. Control angiograms performed through an arterial microcatheter and guide catheter are essential to providing the roadmap for navigation through the venous system, and superselective injections through the arterial microcatheter allow for better characterization of the nidus and optimal positioning of the venous microcatheter. Furthermore, embolic agents can be injected through the arterial microcatheter if necessary, in instances of intraprocedural AVM rupture or residual nidus following transvenous embolization. ${ }^{40}$ Previously, transjugular access using a triaxial system was routinely used for transvenous AVM embolization. Transjugular access allows a microcatheter that has been entrapped in the embolic cast to be cut at the neck, to avoid induction of a cardiac arrhythmia by a retained microcatheter traversing the heart, as would be the case with transfemoral venous access. ${ }^{34}$ Newer microcatheters with detachable tips allow for safer microcatheter removal after embolization, thereby improving the feasibility of transfemoral access for transvenous AVM embolization..$^{23}$

Preservation of the venous outflow until complete nidal obliteration remains the primary challenge of the transvenous approach, as premature venous occlusion can result in nidus engorgement, elevated intranidal pressure, and ensuing AVM rupture. The TRENSH technique, via decreased intranidal pressure gradient, allows for retrograde filling of the nidus and closure of arteriovenous shunting with minimal reflux. In addition, positioning the venous microcatheter as close as possible to the nidus reduces the risk of venous reflux. The neurointerventionalist's knowledge and understanding of an AVM's venous drainage pattern is essential to avoiding premature venous drainage occlusion. AVMs with multiple draining veins are considered safer for the transvenous approach because reflux of excess embolysate into accessory venous outflow channels avoids premature occlusion of the vein accessed by the microcatheter. ${ }^{4,20}$ However, the TRENSH technique was only tested in a single draining vein model, and controlling embolysate permeation of the nidus may be easier in AVMs with a single draining vein. ${ }^{4}$

As demonstrated in the TRENSH technique, induced hypotension, systemically and locally at the AVM nidus, is essential to overcoming the feeding arterial pressure by the embolysate and its retrograde penetration of the nidus. Although the balance between the extent of feasible hypotension and optimal retrograde nidus penetration by embolysate remains unknown, the transnidal pressure 
gradient largely determines the extent of embolysate permeation. ${ }^{36}$ In addition, positioning of a balloon occlusion catheter at the feeding artery allows flow arrest within the nidus via temporary balloon inflation. Balloon occlusion of arterial feeders in the swine AVM model using the TRENSH technique by Massoud demonstrated a decreased transnidal pressure gradient and improved retrograde filling of the nidus. ${ }^{36} \mathrm{~A}$ dramatic reduction in draining vein pressure, with loss of pulsatile venous pattern, can be observed with occlusion of an AVM's arterial feeders. ${ }^{42}$ Hence, in addition to allowing embolization of the transvenously inaccessible portions of the nidus, transarterial access can aid in achieving local hypotension to facilitate transvenous embolization.

Traditional embolic agents used in AVM embolization are polyvinyl alcohol particles, coils, silastic spheres, silk sutures, and ethanol. ${ }^{9,10}$ Liquid embolysates used for AVMs include $N$-butyl cyanoacrylate (NBCA), ethylene vinyl alcohol copolymer (Onyx, ev3 Neurovascular), and more recently, precipitating hydrophobic injectable liquid (PHIL) ${ }^{33,50}$ Compared to NBCA, Onyx laminates along the vessel wall, and is both less adhesive and more cohesive. Due to the rapidity of its polymerization, NBCA is not suitable for transvenous embolization, as immediate occlusion of the draining vein can be disastrous. ${ }^{4}$ The slower polymerization rate and cohesive nature of Onyx allows it to be injected over a period of several minutes to over an hour for a more controlled embolization. In contrast to the transarterial approach, Onyx injection time in the draining vein should be as short as possible to form the initial plug, and the time interval to resume injection is also shorter (approximately 20 seconds) compared to arterial embolizations. ${ }^{40}$ Coils may be deployed upstream to the draining vein prior to Onyx injection to limit reflux of the embolysate, premature draining vein occlusion, and pulmonary embolism. ${ }^{40,56}$ Additionally, balloon inflation at the juncture of the draining vein and dural venous sinus during Onyx injection may increase the venous resistance and improve its retrograde penetration. ${ }^{40}$

\section{Indications}

The indications for transvenous embolization of AVMs have yet to be rigorously assessed and validated. Most of the indications proposed in the literature suggest the transvenous approach as a salvage therapy. $4,25,34,40,46,56$ Relative indications for the transvenous approach included a small and compact AVM nidus ( $<3 \mathrm{~cm}$ in maximum diameter), deep-seated AVMs with a high operative risk, and ruptured AVMs. Although AVMs with multiple draining veins may have built-in mechanisms to allow egress of refluxed embolysate, those with single draining veins are often considered more favorable for the transvenous approach, as nidal penetration is more easily achieved. Additional indications for the transvenous approach are AVMs without safe arterial access, including those with no clearly defined arterial pedicle, tiny perforating arteries, and en passage feeding arteries. Inaccessible nidal remnants identifiable by a persistent draining vein after transarterial embolization, incomplete microsurgery, or failed stereotactic radiosurgery are also reasonable candidates for transvenous embolization. Lastly, the transvenous approach may be used in combination with transarterial embolization in cases for which the goal is endovascular cure.

We illustrate the case of a 38-year-old man with a history of intraventricular hemorrhage from a ruptured, small tectal AVM that was treated using Onyx via the transvenous approach (Fig. 1). The AVM was supplied by perforating branches arising from the right superior cerebellar artery, and the venous drainage was exclusively deep through the right internal cerebral vein (ICV). The final angiogram following transvenous embolization demonstrated complete obliteration of the AVM nidus, with parent artery preservation. There were no procedural complications. The patient remained clinically stable and was discharged 3 days later.

\section{Outcomes}

Table 1 summarizes the baseline characteristics and outcomes of transvenous AVM embolization reported in the literature. The literature review included 13 studies, comprising 69 patients with 70 AVMs that were treated with transvenous embolization. 2,7,26,29,35,39,40,43,44,46,48,54,56 The treated AVMs ranged between $<1$ and $5 \mathrm{~cm}$ in maximum diameter, and the Spetzler-Martin grade (reported in 68 of 70 cases) was I in 7 AVMs (10\%), II in 25 (37\%), III in $24(35 \%)$, and IV in 12 (18\%). ${ }^{51}$ Embolic agents used included Onyx, PHIL, coils, and Glubran (GEM Srl). The majority of the AVMs had a single draining vein $(81 \%)$ and were ruptured (71\%). Most of these AVMs were supplied by small arterial feeders that were challenging to selectively catheterize. Complete AVM obliteration was achieved in $93 \%$ of cases for which the intent of treatment was curative embolization. The complication rate was modest $(4.3 \%)$. However, it is important to note that these cases were highly selected, based on angiographic features, for transvenous embolization. With the relatively modest number of transvenous AVM embolization cases reported in the literature, one should note that the majority of the cases were derived from studies by Mendes et al. ${ }^{39,40}$ Therefore, given the aforementioned indications, the reported outcomes of the transvenous approach may not be generalizable to all AVMs.

In the largest case series to date, comprising 40 patients who underwent transvenous embolization of 41 AVMs, Mendes et al. reported an obliteration rate of $92.6 \%{ }^{40}$ Hemorrhagic presentation was noted in $67.5 \%$ of patients, and all patients underwent transvenous embolization with an intent to cure. A single draining vein was noted in $75 \%$ of AVMs, and 54\% had deep venous drainage. A combination of Onyx, PHIL, and coils were used. A single transvenous embolization session was performed in $56 \%$ of cases, transarterial embolization prior to transvenous intervention was performed in $27 \%$, and combined transarterial and transvenous embolization was performed in $17 \%$. There were 2 complications (5\%), including 1 case of intraprocedural venous rupture and another case of hemorrhagic transformation of a perinidal venous infarct. No procedure-related mortality was observed. Prior to the first embolization session, $75 \%$ of patients had no significant clinical impairment (modified Rankin Scale [mRS] 

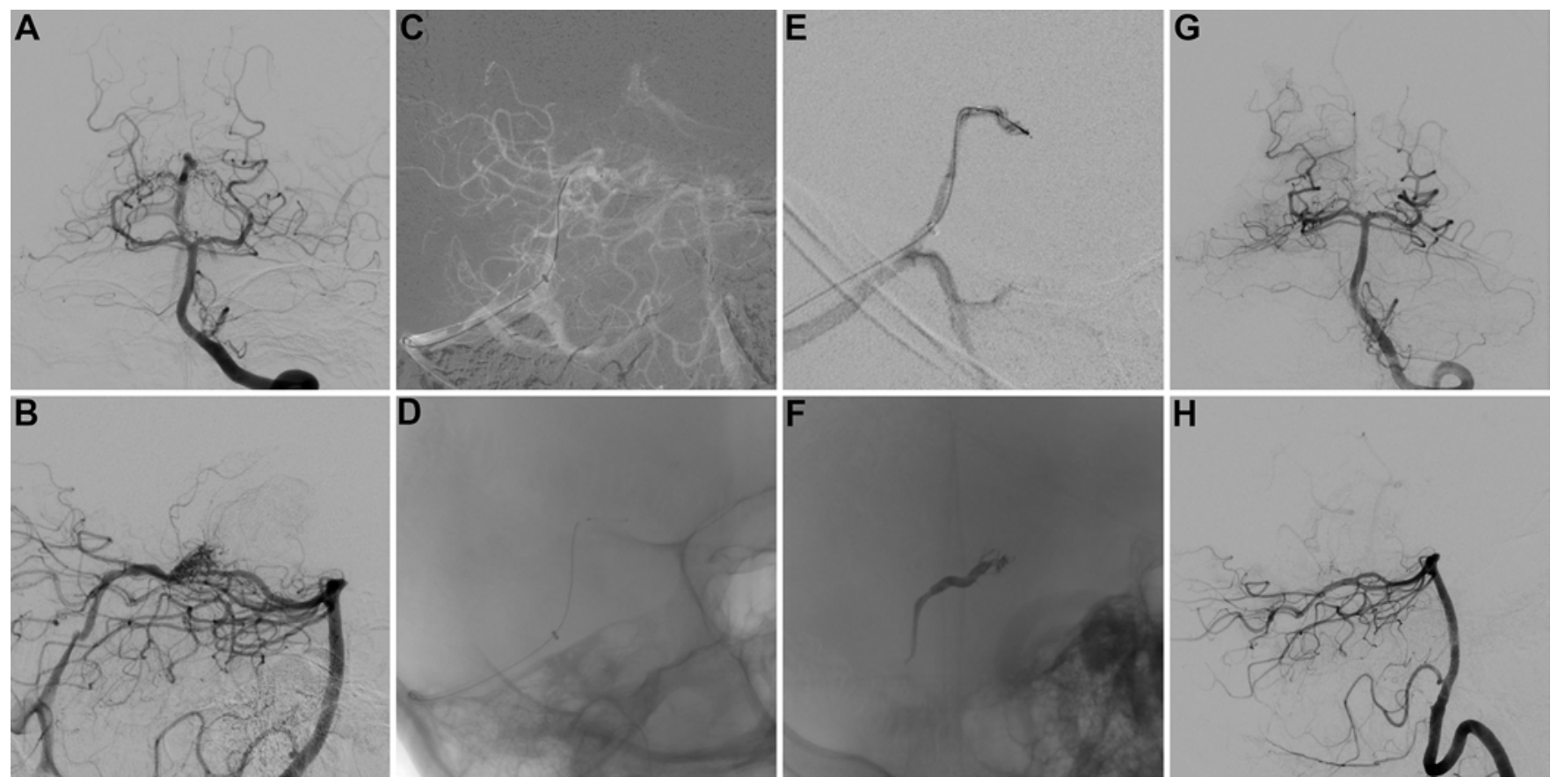

FIG. 1. Images obtained in a 38-year-old man with a history of intraventricular hemorrhage from a ruptured, small tectal AVM. Anteroposterior (A) and lateral (B) digital subtraction angiography (DSA) of the vertebrobasilar circulation from a left vertebral artery contrast injection demonstrated a small tectal AVM with arterial supply from small perforating branches arising from the distal right superior cerebellar artery. Venous drainage was through the right ICV. After obtaining transvenous access via the right internal jugular vein, a SOFIA distal access catheter (MicroVention, Inc.) was navigated into the proximal straight sinus under roadmap guidance (C). Subsequently, an Apollo microcatheter (Medtronic, Inc.) was navigated through the right ICV into the AVM nidus. An unsubtracted radiograph (D) shows the final positions of the distal access catheter and microcatheter. Superselective angiography through a microcatheter injection (E) confirmed an optimal position of the microcatheter tip. Onyx was injected transvenously into the AVM nidus through the microcatheter, and approximately $2 \mathrm{~cm}$ of embolysate reflux was encountered prior to achieving sufficient retrograde nidal penetration $(\mathbf{F})$. Final control DSA, anteroposterior $(\mathbf{G})$ and lateral $(\mathbf{H})$ projections of a left vertebral artery injection, demonstrated complete obliteration of the AVM nidus, with parent artery preservation. There were no procedural complications, and the patient was discharged 3 days later without new or worsening neurological symptoms.

score $<3$ ), and significant disability (mRS score $\geq 3$ ) was observed in 1 patient (2.5\%) at 6-month follow-up.

\section{Complications}

Among the cases reported in the literature, 3 complications associated with transvenous AVM embolization have been reported, yielding an overall complication rate of $4.3 \%$. Trivelato et al. reported a case of transient right cranial nerve V1 hypoesthesia with right lateral pontine surface edema on MRI following transvenous embolization of an 8-mm right middle cerebellar peduncle AVM supplied by a duplicated right superior cerebellar artery and right internal auditory artery arising from the basilar trunk. ${ }^{54}$ The venous drainage was into the right superior petrosal sinus via the superior petrosal vein. The microcatheter was navigated through the superior petrosal sinus and vein, and eventually positioned in the AVM nidus. Embolization was performed using Onyx, which was injected over 22 minutes. There was a significant amount of Onyx reflux toward the venous side of the nidus, and thus the microcatheter was cut at the level of the venous sheath in the internal jugular vein. This case highlights the importance of limiting reflux of the embolysate.

Various techniques, including coil deployment up- stream to the draining vein prior to Onyx injection and balloon inflation at the draining vein-dural venous sinus juncture during Onyx injection, may increase venous resistance and prevent excessive reflux ${ }^{40,56}$ Mendes et al. described 2 complications in their experience of treating 41 AVMs in 40 patients with transvenous embolization..$^{40}$ One patient suffered subarachnoid hemorrhage due to microcatheter perforation during navigation through a cortical vein. There was no clinical sequela associated with the venous perforation. The other patient developed a venous infarct due to venous outflow occlusion, which resulted in transient hemiparesis. The deficit improved to the patient's preoperative baseline at 6-month follow-up. This case again underscores the risk of venous reflux and premature draining vein occlusion-associated transvenous AVM embolization. Therefore, in addition to understanding an AVM's angioarchitecture and careful selection of appropriate lesions, optimizing the microcatheter position in relation to the draining vein and minimizing venous reflux are essential to safely employing this technique.

\section{Conclusions}

For a highly selected subset of AVMs, endovascular cure can be achieved with transvenous embolization in the 


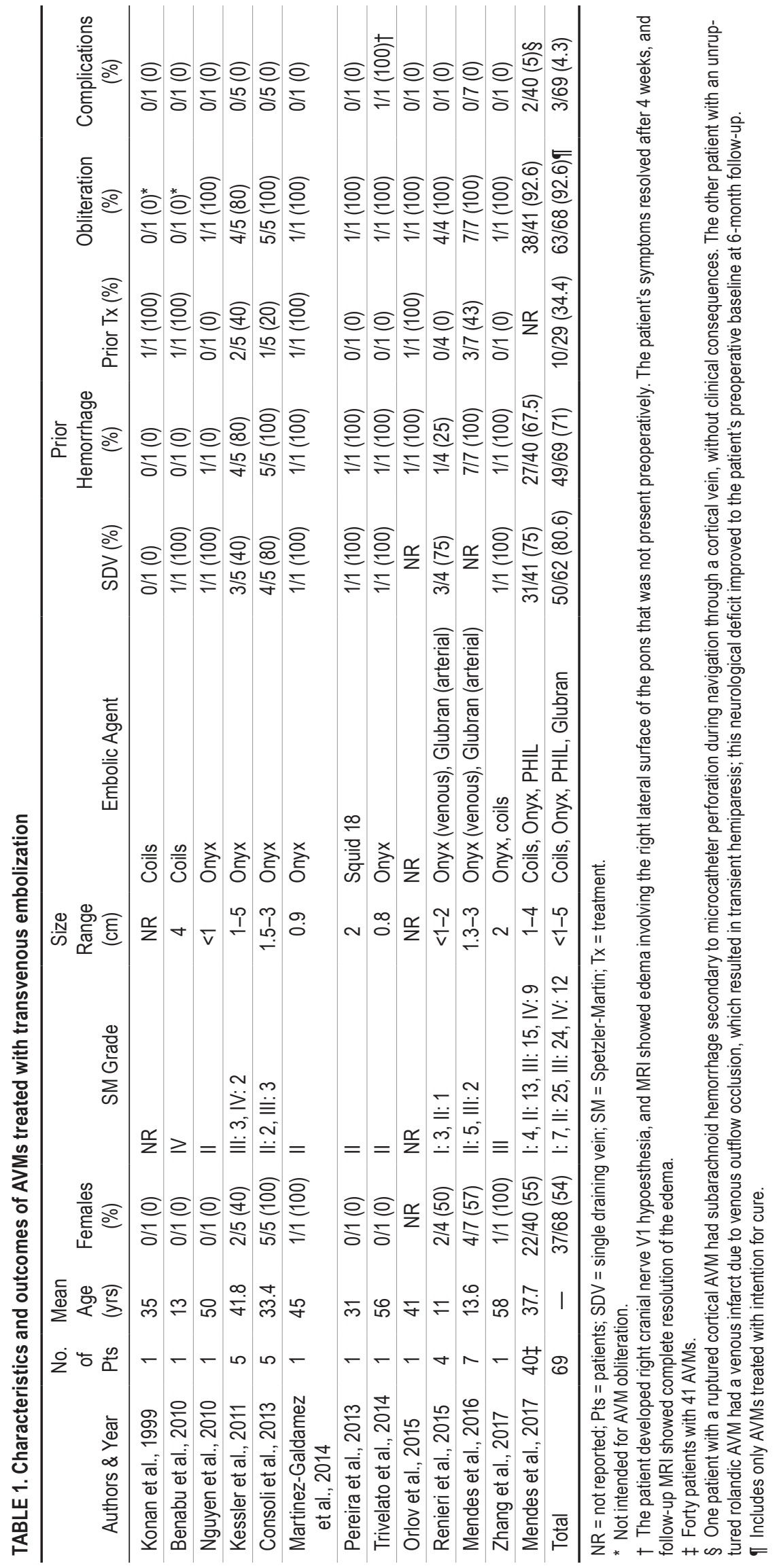


majority of cases. Currently, the transvenous approach is considered an unproven salvage therapy in the contemporary management of AVMs. Relative indications for transvenous embolization include a small and compact AVM nidus, deep AVM location, hemorrhagic presentation, single draining vein, lack of a navigable arterial feeder, and inaccessible nidal remnant. Currently, the risk-to-benefit profile of transvenous AVM embolization is incompletely defined due to the modest number of reported cases in the literature and limited posttreatment follow-up. Additionally, the long-term rates of nidal recanalization with this technique are poorly understood. Therefore, future studies comprising larger cohorts are needed to refine the indications and delineate the outcomes of transvenous embolization for AVMs.

\section{References}

1. Al-Shahi R, Warlow C: A systematic review of the frequency and prognosis of arteriovenous malformations of the brain in adults. Brain 124:1900-1926, 2001

2. Benabu Y, Roy D, Guilbert F, Raymond J, Weill A: Transvenous embolization of a symptomatic venous aneurysm developing in the drainage network of a deep cerebral AVM: a case report. J Neuroimaging 20:373-375, 2010

3. Brown RD Jr, Wiebers DO, Forbes GS: Unruptured intracranial aneurysms and arteriovenous malformations: frequency of intracranial hemorrhage and relationship of lesions. J Neurosurg 73:859-863, 1990

4. Choudhri O, Ivan ME, Lawton MT: Transvenous approach to intracranial arteriovenous malformations: challenging the axioms of arteriovenous malformation therapy? Neurosurgery 77:644-652, 2015

5. Cohen-Inbar O, Ding D, Chen CJ, Sheehan JP: Stereotactic radiosurgery for deep intracranial arteriovenous malformations, part 1: brainstem arteriovenous malformations. J Clin Neurosci 24:30-36, 2016

6. Conger JR, Ding D, Raper DM, Starke RM, Durst CR, Liu $\mathrm{KC}$, et al: Preoperative embolization of cerebral arteriovenous malformations with silk suture and particles: technical considerations and outcomes. J Cerebrovasc Endovasc Neurosurg 18:90-99, 2016

7. Consoli A, Renieri L, Nappini S, Limbucci N, Mangiafico S: Endovascular treatment of deep hemorrhagic brain arteriovenous malformations with transvenous onyx embolization. AJNR Am J Neuroradiol 34:1805-1811, 2013

8. Crowley RW, Ducruet AF, McDougall CG, Albuquerque FC: Endovascular advances for brain arteriovenous malformations. Neurosurgery 74 (Suppl 1):S74-S82, 2014

9. Dehdashti AR, Muster M, Reverdin A, de Tribolet N, Ruefenacht DA: Preoperative silk suture embolization of cerebral and dural arteriovenous malformations. Neurosurg Focus 11(5):e6, 2001

10. Ding D, Sheehan JP, Starke RM, Durst CR, Raper DM, Conger JR, et al: Embolization of cerebral arteriovenous malformations with silk suture particles prior to stereotactic radiosurgery. J Clin Neurosci 22:1643-1649, 2015

11. Ding D, Starke RM, Kano H, Lee JY, Mathieu D, Pierce J, et al: Stereotactic radiosurgery for Spetzler-Martin Grade III arteriovenous malformations: an international multicenter study. J Neurosurg 126:859-871, 2017

12. Ding D, Starke RM, Kano H, Lee JYK, Mathieu D, Pierce J, et al: Radiosurgery for unruptured brain arteriovenous malformations: an international multicenter retrospective cohort study. Neurosurgery 80:888-898, 2017

13. Ding D, Starke RM, Kano H, Mathieu D, Huang PP, Feliciano C, et al: International multicenter cohort study of pedi- atric brain arteriovenous malformations. Part 1: predictors of hemorrhagic presentation. J Neurosurg Pediatr 19:127-135, 2017

14. Ding D, Starke RM, Quigg M, Yen CP, Przybylowski CJ, Dodson BK, et al: Cerebral arteriovenous malformations and epilepsy, part 1: predictors of seizure presentation. World Neurosurg 84:645-652, 2015

15. Ding D, Starke RM, Sheehan JP: Radiosurgery for the management of cerebral arteriovenous malformations. Handb Clin Neurol 143:69-83, 2017

16. Ding D, Xu Z, Starke RM, Yen CP, Shih HH, Buell TJ, et al: Radiosurgery for cerebral arteriovenous malformations with associated arterial aneurysms. World Neurosurg 87:77-90, 2016

17. Doppman JL: The nidus concept of spinal cord arteriovenous malformations. A surgical recommendation based upon angiographic observations. Br J Radiol 44:758-763, 1971

18. Dumont TM, Kan P, Snyder KV, Hopkins LN, Siddiqui AH, Levy EI: A proposed grading system for endovascular treatment of cerebral arteriovenous malformations: Buffalo score. Surg Neurol Int 6:3, 2015

19. Gross BA, Du R: Natural history of cerebral arteriovenous malformations: a meta-analysis. J Neurosurg 118:437-443, 2013

20. Hademenos GJ, Massoud TF: Risk of intracranial arteriovenous malformation rupture due to venous drainage impairment. A theoretical analysis. Stroke 27:1072-1083, 1996

21. Halbach VV, Higashida RT, Hieshima GB, Hardin CW, Pribram H: Transvenous embolization of dural fistulas involving the cavernous sinus. AJNR Am J Neuroradiol 10:377-383, 1989

22. Halbach VV, Higashida RT, Hieshima GB, Mehringer CM, Hardin CW: Transvenous embolization of dural fistulas involving the transverse and sigmoid sinuses. AJNR Am J Neuroradiol 10:385-392, 1989

23. Herial NA, Khan AA, Sherr GT, Qureshi MH, Suri MF, Qureshi AI: Detachable-tip microcatheters for liquid embolization of brain arteriovenous malformations and fistulas: a United States single-center experience. Neurosurgery 11 (Suppl 3):404-411, 2015

24. Houdart E, Gobin YP, Casasco A, Aymard A, Herbreteau D, Merland JJ: A proposed angiographic classification of intracranial arteriovenous fistulae and malformations. Neuroradiology 35:381-385, 1993

25. Iosif C, Mendes GA, Saleme S, Ponomarjova S, Silveira EP, Caire F, et al: Endovascular transvenous cure for ruptured brain arteriovenous malformations in complex cases with high Spetzler-Martin grades. J Neurosurg 122:1229-1238, 2015

26. Kessler I, Riva R, Ruggiero M, Manisor M, Al-Khawaldeh M, Mounayer C: Successful transvenous embolization of brain arteriovenous malformations using Onyx in five consecutive patients. Neurosurgery 69:184-193, 2011

27. Kim H, Abla AA, Nelson J, McCulloch CE, Bervini D, Morgan MK, et al: Validation of the supplemented Spetzler-Martin grading system for brain arteriovenous malformations in a multicenter cohort of 1009 surgical patients. Neurosurgery 76:25-33, 2015

28. Kim H, Al-Shahi Salman R, McCulloch CE, Stapf C, Young WL: Untreated brain arteriovenous malformation: patientlevel meta-analysis of hemorrhage predictors. Neurology 83:590-597, 2014

29. Konan AV, Roy D, Raymond J: Endovascular treatment of hemifacial spasm associated with a cerebral arteriovenous malformation using transvenous embolization: case report. Neurosurgery 44:663-666, 1999

30. Lasjaunias P, Manelfe C, Chiu M: Angiographic architecture of intracranial vascular malformations and fistulas-pretherapeutic aspects. Neurosurg Rev 9:253-263, 1986 
31. Lawton MT, Du R, Tran MN, Achrol AS, McCulloch CE, Johnston SC, et al: Effect of presenting hemorrhage on outcome after microsurgical resection of brain arteriovenous malformations. Neurosurgery 56:485-493, 2005

32. Lawton MT, Kim H, McCulloch CE, Mikhak B, Young WL: A supplementary grading scale for selecting patients with brain arteriovenous malformations for surgery. Neurosurgery 66:702-713, 2010

33. Loh Y, Duckwiler GR: A prospective, multicenter, randomized trial of the Onyx liquid embolic system and N-butyl cyanoacrylate embolization of cerebral arteriovenous malformations. Clinical article. J Neurosurg 113:733-741, 2010

34. Lv X, Song C, He H, Jiang C, Li Y: Transvenous retrograde AVM embolization: indications, techniques, complications and outcomes. Interv Neuroradiol 23:504-509, 2017

35. Martinez-Galdamez M, Saura P, Saura J, Muniz J, Albisua J, Perez-Higueras A: Transvenous Onyx embolization of a subependymal deep arteriovenous malformation with a single drainage vein: technical note. J Neurointerv Surg 6:e20, 2014

36. Massoud TF: Transvenous retrograde nidus sclerotherapy under controlled hypotension (TRENSH): hemodynamic analysis and concept validation in a pig arteriovenous malformation model. Neurosurgery 73:332-343, 2013

37. Massoud TF, Hademenos GJ: Transvenous retrograde nidus sclerotherapy under controlled hypotension (TRENSH): a newly proposed treatment for brain arteriovenous malformations-concepts and rationale. Neurosurgery 45:351-365, 1999

38. Massoud TF, Hademenos GJ, Young WL, Gao E, Pile-Spellman J: Can induction of systemic hypotension help prevent nidus rupture complicating arteriovenous malformation embolization?: analysis of underlying mechanism achieved using a theoretical model. AJNR Am J Neuroradiol 21:12551267,2000

39. Mendes GA, Iosif C, Silveira EP, Waihrich E, Saleme S, Mounayer C: Transvenous embolization in pediatric plexiform arteriovenous malformations. Neurosurgery 78:458465, 2016

40. Mendes GAC, Kalani MYS, Iosif C, Lucena AF, Carvalho R, Saleme S, et al: Transvenous curative embolization of cerebral arteriovenous malformations: a prospective cohort study. Neurosurgery [epub ahead of print], 2017

41. Mouchtouris N, Jabbour PM, Starke RM, Hasan DM, Zanaty M, Theofanis T, et al: Biology of cerebral arteriovenous malformations with a focus on inflammation. J Cereb Blood Flow Metab 35:167-175, 2015

42. Murayama Y, Usami S, Hata Y, Ganaha F, Hasegawa Y, Terao T, et al: Transvenous hemodynamic assessment of arteriovenous malformations and fistulas. Preliminary clinical experience in Doppler guidewire monitoring of embolotherapy. Stroke 27:1358-1364, 1996

43. Nguyen TN, Chin LS, Souza R, Norbash AM: Transvenous embolization of a ruptured cerebral arteriovenous malformation with en-passage arterial supply: initial case report. J Neurointerv Surg 2:150-152, 2010

44. Orlov KY, Berestov VV, Krivoshapkin AL, Panarin VA, Kislitsin DS, Gorbatykh AV, et al: [Transarterial and transvenous embolization of deep binodal arteriovenous malformation of the brain.] Zh Vopr Neirokhir Im N N Burdenko 79:85-89, 2015 (Russian)

45. Patibandla MR, Ding D, Kano H, Xu Z, Lee JYK, Mathieu $D$, et al: Stereotactic radiosurgery for Spetzler-Martin Grade IV and V arteriovenous malformations: an international mul- ticenter study. J Neurosurg [epub ahead of print September 8, 2017. DOI: 10.3171/2017.3.JNS162635]

46. Pereira VM, Marcos-Gonzalez A, Radovanovic I, Bijlenga P, Narata AP, Moret J, et al: Transvenous embolization of a ruptured deep cerebral arteriovenous malformation. A technical note. Interv Neuroradiol 19:27-34, 2013

47. Redekop G, TerBrugge K, Montanera W, Willinsky R: Arterial aneurysms associated with cerebral arteriovenous malformations: classification, incidence, and risk of hemorrhage. J Neurosurg 89:539-546, 1998

48. Renieri L, Limbucci N, Consoli A, Rosi A, Nappini S, Giordano F, et al: Transvenous embolization: a report of 4 pediatric cases. J Neurosurg Pediatr 15:445-450, 2015

49. Saatci I, Geyik S, Yavuz K, Cekirge HS: Endovascular treatment of brain arteriovenous malformations with prolonged intranidal Onyx injection technique: long-term results in 350 consecutive patients with completed endovascular treatment course. J Neurosurg 115:78-88, 2011

50. Samaniego EA, Kalousek V, Abdo G, Ortega-Gutierrez S: Preliminary experience with precipitating hydrophobic injectable liquid (PHIL) in treating cerebral AVMs. J Neurointerv Surg [epub ahead of print], 2016

51. Spetzler RF, Martin NA: A proposed grading system for arteriovenous malformations. J Neurosurg 65:476-483, 1986

52. Spetzler RF, Ponce FA: A 3-tier classification of cerebral arteriovenous malformations. Clinical article. J Neurosurg 114:842-849, 2011

53. Starke RM, Kano H, Ding D, Lee JY, Mathieu D, Whitesell $\mathrm{J}$, et al: Stereotactic radiosurgery for cerebral arteriovenous malformations: evaluation of long-term outcomes in a multicenter cohort. J Neurosurg 126:36-44, 2017

54. Trivelato FP, Manzato LB, Rezende MT, Ulhôa AC: Transitory brain stem edema following successfully transvenous embolization of a posterior fossa arteriovenous malformation. Clin Neuroradiol 24:151-153, 2014

55. Winkler EA, Birk H, Burkhardt JK, Chen X, Yue JK, Guo D, et al: Reductions in brain pericytes are associated with arteriovenous malformation vascular instability. J Neurosurg [epub ahead of print January 5, 2018. DOI: 10.3171/2017.6.JNS17860]

56. Zhang G, Zhu S, Wu P, Xu S, Shi H: The transvenous pressure cooker technique: A treatment for brain arteriovenous malformations. Interv Neuroradiol 23:194-199, 2017

\section{Disclosures}

The authors report no conflict of interest concerning the materials or methods used in this study or the findings specified in this paper.

\section{Author Contributions}

Conception and design: Kalani. Acquisition of data: Chen, Norat. Analysis and interpretation of data: Chen, Norat. Drafting the article: Chen, Norat. Critically revising the article: all authors. Reviewed submitted version of manuscript: all authors. Approved the final version of the manuscript on behalf of all authors: Kalani. Statistical analysis: Chen. Administrative/technical/material support: Kalani. Study supervision: Kalani.

\section{Correspondence}

M. Yashar S. Kalani: University of Virginia Health System, Charlottesville,VA.yk6z@hscmail.mcc.virginia.edu. 